\title{
Regulaciones, inmigrantes y empresas: Prácticas de consumo en la actividad minorista tradicional de la tienda de barrio durante el siglo XX en Barranquilla (Colombia)
}

\author{
Regulations, Immigrants and Companies: Consumption \\ Practices in Traditional Retailers in Local Groceries \\ in Barranquilla (Colombia) in the $20^{\text {th }}$ Century
}

Margarita María Contreras Cuentas, ORCID iD: http://orcid.org/0000-0001-8728-1535 Universidad del Norte, Barranquilla, Colombia

Dagoberto Páramo Morales, ORCID iD: http://orcid.org/0000-0002-2044-6179

Universidad del Norte, Barranquilla, Colombia

Yolmis Nicolás Rojano Alvarado, ORCID iD: http://orcid.org/0000-0003-1389-3875

Universidad de La Guajira, Riohacha, Colombia

La tienda de barrio proliferó en Barranquilla durante el siglo XX, llevó a los consumidores periféricos de la ciudad gran variedad de productos de la canasta familiar, relegando el uso de los mercados públicos. El artículo, combinando etnografía, aportes antropológicos y análisis de fuentes primarias y literarias, describe la regulación estatal y los modelos comerciales de extranjeros y de migrantes nacionales que complementaron estrategias empresariales en la tienda de barrio barranquillera, institucionalizadas y resguardadas en su inventario histórico.

PAlabras ClaVE: Tienda de Barrio; Regulaciones; Inmigrantes; Empresas; Comercialización.

Retail business flourished in Barranquilla during the twentieth century, bringing peripheral consumers of the city a great variety of products of the market basket, relegating the use of public markets. The article, combining ethnography, anthropological contributions and analysis of primary and literary sources, describes the state regulation and the business models of foreigners and national migrants that complemented business strategies in the Barranquilla local groceries, preserved and recognized as part of the local heritage.

KeYwords: Local Business; Regulations; Immigrants; Companies; Trade.

Copyright: (C) 2020 CSIC. Este es un artículo de acceso abierto distribuido bajo los términos de la licencia de uso y distribución Creative Commons Reconocimiento 4.0 Internacional (CC BY 4.0). 


\section{Introducción}

La tienda tradicional en los países de América ${ }^{1}$ sintetiza parte del legado de las tiendas de ultramarinos, caracterizadas por comercializar productos importados provenientes de España, y se materializa en una especie de fusión entre actividades comerciales y sociales que, aunque con algunas diferencias entre ellos, son conocidos con términos y expresiones distintas: «bodegas» en Cuba y Venezuela; «pulperías» en Argentina, Chile y Costa Rica; «almacenes» en Uruguay, «abarrotes» en algunas regiones de México y «tiendas de barrio» en Colombia, Perú y Ecuador. ${ }^{2}$ En Colombia, estos canales minoristas tradicionales de comercialización, se convirtieron en una alternativa de venta y adquisición de todo tipo de víveres y abarrotes.

A pesar de la dura y no siempre leal competencia enfrentada por las tiendas de barrio con toda la carga cultural que ellas llevan consigo, heredada de la tradición colombiana proveniente de esa particular configuración de los trazos de nacionalidad que nos identifica, han sabido mantenerse firmes y de pie, han soportado tormentas de todo tipo. Los subgrupos dentro de las naciones están escondidos en la historia, que al ser transferido de generación en generación esta pequeña diferencia creció cada vez más, hasta que se hizo tan grande como lo conocemos hoy. ${ }^{3}$ Esta inocultable circunstancia de la realidad colombiana, y en particular de una ciudad como Barranquilla, en la que confluyen mundos tan contrastantes que hacen imposible separar sus matices como en un mosaico cultural que ayude a descubrir sus complejidades, es suficientemente motivante para abordar su estudio en su devenir histórico que le dé sentido a su existencia. Por ello, aproximarse de manera preliminar y exploratoria al consumo que se ha tejido a su alrededor, no ha dejado de ser un reto en la historia para quienes, convencidos de entenderse como una realidad multiétnica, han estado decididos a seguir profundizando en sus más recónditas expresiones comerciales.

1 En algunas partes del mundo el resguardo a la pequeña tienda de barrio se fortalece. Ubicadas económicamente en el «comercio minorista tradicional», en la India estas toman el nombre de «Kiranas». Han sido protegidas por el Estado debido a la autenticidad de su actividad comercial, que es heredada y sostenida por quienes la ejercen. Dholakia, Dholakia y Chattopadhyay, 2012, 256. Otros países como Brasil, China, Zimbabwe, Australia y Filipinas se han acogido a estipulaciones y legislaciones en el sector alimenticio, proliferando los grandes formatos comerciales. Reardon, Timmer, Barrett, y Berdegué, 2003, 1142; Saini y Sahay, 2013, 51.

2 Páramo y Contreras, 2014, 105.

3 Hofstede, 2008, 5. 
En pro de este objetivo, en el presente artículo se abordan de manera sucinta algunos de los aspectos claves que arrojan luces sobre las formas en las que el comerciante tradicional lleva a cabo su labor. Se relacionan técnicas etnográficas, elementos antropológicos para la interpretación de fuentes orales (entrevistas estructuradas, semiestructuradas y discusiones de grupos), análisis de fuentes primarias, y documentos de literatura, ${ }^{4}$ para presentar algunas características del consumo popular y algunos aspectos generales de la tienda de barrio, con lo que se busca dimensionar parte de sus propias circunstancias. Siguiendo la teoría Russell Belk relacionada con la cultura y el consumo - que informa y sostiene el deseo de quien adquiere los productos- es probable que estemos ante una actividad culturalmente variable e influenciada por las creencias existenciales básicas que están implicadas en nuestro diario vivir. ${ }^{5}$

$\mathrm{Al}$ principio del siglo $\mathrm{XX}$, un gran número de productos artesanales y agrícolas ocupaban las estanterías de las tiendas de barrio, y a mediados del siglo la fuerza comercial de importadores, empresas y productores hacían alianza para dar a conocer la variedad de productos de consumo familiar. En este documento, se develan características de las prácticas comerciales que cubrían el consumo local, el tipo de productos que se expendían y consumían, y las clases de consumidores que los adquirían haciendo frente a las vicisitudes del mercado. Para lograrlo, se realizó un análisis riguroso de las fuentes orales de personas que vivieron los choques culturales de mediados del siglo XX respecto a las actividades comerciales, y del necesario ajuste de las estructuras del mercado en la tienda de barrio; se incluyen también las decisiones regulatorias de la época, los contenidos de noticias y publicidades de las que se lograron extraer y organizar los hechos más relevantes relacionados con el consumo.

\section{El consumo popular y la tienda de barrio en Barranquilla}

La dinámica comercial de Colombia con mercados europeos en el siglo XIX dio paso a la creación de sociedades mercantiles locales. Esta

4 La etnografía es el método científico de la antropología cultural que recurre a la observación in situ y a la entrevista en profundidad. Últimamente ha sido ampliamente utilizado en la investigación del consumidor, tanto en el mundo académico como en el empresarial. Dominique y Gómez-Corona, $2018,1$.

5 Belk, Ger y Askegaard, 1975, 348. Belk, 1985, 5. Belk, 2003, 158. 
influencia permitió el establecimiento de «casas comerciales» que se lucraban de las actividades especulativas derivadas del comercio, especialmente en sus funciones de prestamista, permitiendo financiar grandes obras de carácter local y regional. Ejemplo de ello fue la ampliación de la línea férrea del ferrocarril Bolívar, desde Salgar hasta Puerto Cupino, hoy conocido como Puerto Colombia. ${ }^{6}$

A finales del siglo XIX, «gracias a su dinámica comercial y portuaria la ciudad de Barranquilla logro consolidarse como el primer epicentro del comercio nacional, motivando la llegada de un gran número de comerciantes nacionales y extranjeros, quienes se lucraban de las actividades relacionadas con el comercio de exportación e importación». ${ }^{7}$ La entrada del siglo XX trajo consigo cambios en las formas y estructuras de distribución en los canales tradicionales de amplia raigambre popular. Estos tuvieron que hacer frente a inesperadas dinámicas sociales como resultado de los profundos cambios demográficos y de integración cultural experimentados en la Colombia de la época. El consumo urbano se incrementaba de forma incesante dados los crecientes flujos poblacionales que abandonaban el campo en busca de mejores condiciones de vida. ${ }^{8}$ La progresiva demanda de productos como queso, mantequilla, sebo, cueros, velas y jabones exigió un sensible ajuste en los flujos comerciales y en la cadena de distribución a fin de hacer frente a estas nuevas realidades prevalecientes. ${ }^{9}$ Fue así como varias residencias de las urbes, en las que existían locales comerciales que ofrecían todo tipo de productos artesanales, fueron tomadas por capataces de las familias hacendadas con el propósito de usar las habitaciones ubicadas hacia la calle y emplearlas como tiendas, a la vez que utilizaban el resto de la edificación como hogar de sus familias.

Desde entonces, las tiendas de barrio, además de cumplir su función básica de expender productos de consumo popular, se fueron convirtiendo en espacios rutinarios y de activos intercambios de habladurías entre amigos y vecinos, a la vez que les daban cabida a las discusiones políticas. ${ }^{10}$ Desde la perspectiva de los concurrentes compradores, la tienda de barrio es como un centro social donde se encuentran amigos y vecinos. ${ }^{11} \mathrm{~A}$ comienzos de 1900 en Barranquilla, los cambios en el ambiente comercial

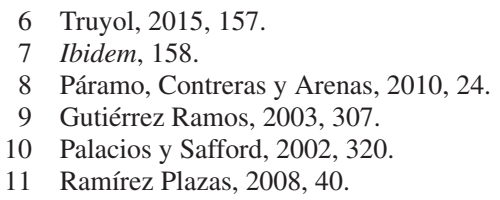


fueron notables. El arribo de inmigrantes extranjeros «alemanes, italianos, cubanos, norteamericanos, franceses, venezolanos, ingleses, sirios, libaneses, palestinos», ${ }^{12}$ y la instauración de las mejores casas comerciales y agencias de vapores, ${ }^{13}$ fortalecieron la actividad económica de la ciudad y el movimiento de las transacciones, ensanchando el creciente mercado local.

En este sentido, de las ciudades capitales en la costa caribe colombiana, «Barranquilla y Cartagena, por su condición de tener más desarrollo industrial, comercial y portuario, son receptoras de las fuertes corrientes migratorias internas; agrupan el $30 \%$ de la población total, en un país con 32 ciudades capitales». ${ }^{14}$ Según la dependencia del entorno, esto ofrece grandes posibilidades de sinergia y de aprender unos de otros en un mundo que exige cada vez más interculturalidad y cooperación..$^{15}$ Otro aspecto importante y determinante para el crecimiento industrial de Barranquilla fue su ubicación geoestratégica, abierta al océano atlántico, que ofrecía múltiples oportunidades comerciales, pues los puertos de su competencia, Cartagena y Santa Marta, presentaban problemas en su operación. Así, Barranquilla se logró consolidar como la principal generadora de ingresos fiscales del país y la primera aduana a nivel nacional en exportación e importación. ${ }^{16}$

Para finales de 1910, La Arenosa ${ }^{17}$ empezó a exhibir su nuevo rostro de tal forma que la reconfiguración comercial tuvo que adaptarse a las renovadas condiciones urbanísticas. La necesidad de irse ajustando a las demandas producidas por los recientes flujos migratorios hizo que el crecimiento físico de la ciudad se alejara de los dos polos tradicionales de desarrollo: el «centro de la ciudad» y el «mercado público», y se extendiera hacia el sur. En 1948, los desplazamientos poblacionales provenientes del interior del país a Barranquilla, representados por las familias que huyeron de la violencia generada después de la muerte de líder liberal Jorge Eliécer Gaitán,

12 Restrepo, 2010, 198.

13 Zarante, 2007, 25.

14 Londoño y Aldana, 2014.

15 Hofstede, 2008, 12

16 Vidal y D'Amato, 2014.

17 La ciudad de Barranquilla es un Distrito Especial, Industrial y Portuario en Colombia, y ha sido identificada con distintos nombres: La Arenosa, La Puerta de Oro de Colombia, El Pórtico de Colombia, La Ciudad Libérrima, La Nueva Orleans de Colombia, La Llave de Oro de Colombia, La Ciudad de los Brazos Abiertos, La Nueva York de Colombia, Curramba la Bella. Viloria et al., 1995, 548-551. 
se radicaron en la ciudad y se sumaron a estos hechos. ${ }^{18}$ Así, la ubicación de los nuevos barrios produjo en su interior una particular simbiosis de intereses entre tenderos ${ }^{19}$ y consumidores, cuyas características fundamentales pueden distinguirse en tres de los barrios más ancestrales de la ciudad:

a) Barrio Abajo: era un barrio en el que la clientela de la tienda la conformaban las familias de los trabajadores y los obreros del ferrocarril y de las factorías ubicadas tanto en las calles principales como en las inmediaciones del sector. ${ }^{20} \mathrm{El}$ consumo en estas tiendas era variado y contrastante, como en la tienda-panadería «Nube Blanca» — fundada en 1928_, en la cual, además de ser una clásica tienda de barrio, se expendían panes de gran reconocimiento local. ${ }^{21}$ Caso similar fue el de la tienda «El Motor», — propiedad de Miguel Barriga_, en la que podía encontrarse gran variedad de abarrotes, utensilios para el hogar, productos de ferretería y todo tipo de remedios caseros, dado que su propietario fungía como médico tegua. ${ }^{22}$ En general, las tiendas del Barrio Abajo contaban con depósitos donde los clientes y compradores podían abastecerse, al por mayor y venta al detalle, de sacos de granos, latas de manteca, herramientas, escobas, traperos, y también elementos que servían para armar fogones donde cocinar la comida como leña, carbón y gas, así como elementos para armar las neveras de palo cubiertas de latas para conservar la comida en hielo. ${ }^{23}$ Asimismo, en estas tiendas se consumían ingredientes de recetas artesanales vendidos en los asentamientos de palenqueros que vivían en el barrio, quienes adquirían las tusas, el maíz, el carbón y el gas para hacer los bollos y los fritos que vendían en la periferia de los barrios. ${ }^{24}$

18 A mediados del siglo XX, el sistema socioeconómico de Colombia es impactado por las ansias de revolución producidas por el asesinato del líder del partido liberal Jorge Eliecer Gaitán, quien movilizaba a la mayoría de los pobladores en busca del logro de sus ideales políticos. En ese tiempo, las guerras bipartidistas aumentaron, el comercio se paralizó y el resentimiento del pueblo generó una lucha desde el interior del país que, a su vez, produjo parte de la migración hacia los departamentos del Caribe colombiano, con gran afluencia a la ciudad de Barraquilla.

19 Páramo y Contreras, 2014, 117.

20 Salcedo, 2008, 5.

21 Don Ramiro, 1928, 348.

22 Barriga y Barriga, 2013,100.

23 Eran notorias las características de las tiendas de barrio que sobrevivieron en el entorno de la época. Aun después de generaciones enteras, las imágenes y los artefactos enaltecen a las familias comerciales, dado que mantienen lo que sus antepasados practicaban en el diario vivir. Entrevista a Gladys Gribaldo Taberas realizada en Barranquilla el 28 de enero de 2014.

24 Muchas de las tiendas de la ciudad llevaban nombres con los cuales se identificaban las antiguas calles y algunas esquinas donde sus pobladores departían y también consumían lo que se les ofrecía. Varias de estas tiendas, pasado el siglo XX, continúan utilizando los mismos nombres. Entrevista a Luis Eduardo Martínez realizada en Barranquilla el 16 de mayo de 2014. 
b) Barrio San Roque: en su interior se establecieron numerosos extranjeros dedicados al comercio ${ }^{25}$ también muchos pobladores que laboraban en talleres, casas comerciales, empresas y demás establecimientos, quienes, al por menor, compraban los productos del diario vivir de sus familias. Entre las tiendas más reconocidas a mediados del siglo XX estaban: «La Dimayor», «El Buen Trato»y «El Canal de Suez», ${ }^{26}$ caracterizadas por ser tiendas misceláneas. Otras tiendas muy reconocidas fueron «El Nevado», «La Batuta», «La Preferida»y «La Carmelita», en cuyas instalaciones se vendían también comidas, sancochos, gallinas y víveres como pastas, arroz y manteca; trabajaban familias tenderas provenientes de los departamentos de Bolívar y Sucre. ${ }^{27}$

c) Barrio Rebolo: sus pobladores, campesinos humildes —en los años cuarenta del siglo XX-, provenían, en su mayoría, de las riberas del Río Magdalena, ${ }^{28}$ y se dedicaban a la venta — en burro- de sus cosechas para abastecer a los tenderos de vegetales, frutas, leche cruda y bastimentos del sancocho. Las tiendas eran de estructura rudimentaria, en casas con paredes de barro, con neveras de petróleo y un reducido número de artículos para vender.

\section{Algunas regulaciones y acciones del Estado sobre el consumo en las tiendas de barrio}

A lo largo del siglo XX, el consumo en las tiendas de barrio en Barranquilla y en el país estuvo marcado por decisiones gubernamentales de política pública dirigidas a controlar el accionar comercial de las tiendas de barrio y sus diversos procesos de inserción en la estructura logística del país. La Ordenanza Departamental del Atlántico n. ${ }^{\circ}$ 87, del 20 de junio de 1947, asignó a la Policía Nacional la función de vigilar las transacciones comerciales y de suspender transitoriamente la venta de víveres o de licores de cualquier clase que aparecieran dañados o que se expendieran en condiciones que amenazaran la salubridad, o cuando en su preparación se

25 Zambrano, 1979, 67.

26 Fábregas, 1996, 68.

27 «La migración interna en Colombia que llegaba a Barranquilla no solo provenía de regiones de clima frío, como la historia lo señala, sino, también se sabe de pobladores de otras regiones del Caribe que se interesaban en llegar a una ciudad cosmopolita, donde asentaban sus negocios y buscaban hacer parte de una pluralidad extranjera y nacional dispersa en toda la extensión de la ciudad». Entrevista a Teresa Ladrón de Guevara realizada en Barranquilla el 4 de junio de 2014. Varios estudios afirman que la migración interna en Colombia en los años 1988-1993 se da en una alta proporción entre los departamentos de la misma región. Galvís, 2002, 111.

28 Dagis, 1996, 28. 
utilizaran elementos nocivos; de igual manera, debían dar cuenta al jefe de policía de manera inmediata para que, previo el correspondiente dictamen, resolviera si podían venderse o no. ${ }^{29}$ Además, se prohibió igualmente salir a los barrios o caminos a acaparar los víveres que iban a expenderse en los mercados, y a obstaculizar de cualquier manera a los conductores de los vehículos en que estos eran transportados. La contravención de este artículo se castigaba con una multa cuyo monto oscilaba entre los cinco y los cincuenta pesos de la época. ${ }^{30}$

La Ley 7 del 2 de marzo de 1943 estableció con claridad el listado de los artículos de primera necesidad demandados por las clases populares de la época: víveres, drogas y mercancías de ordinario consumo. ${ }^{31}$ Por otra parte, la Ley 33 de 1905 precisó el uso de las pesas y medidas del sistema métrico decimal francés para la venta de los productos: metro, área o decámetro cuadrado, litro o decímetro cúbico, gramo o centímetro de agua destilada, tonelada, quintal, arroba, libra, onza, castellano y quilate (unidades usadas por joyeros, aclarando que una libra tenía cien castellanos, un castellano cuatro gramos, una libra dos mil quinientos quilates, un quilate era la quinta parte de un gramo), vara (equivale a ochenta centímetros), yarda, fanegada (unidad de superficie), almud y medio almud (para los gramos), pacha o palito (un cajón de quince centímetros de base por cinco centímetros de altura en la parte interior) y galón (usado para aceites, equivalía a tres litros y sesenta y ocho centésimos de litro). ${ }^{32}$

Frente a estas regulaciones estatales, las tiendas de barrio se vieron enfrentadas a controles que no siempre cumplieron de manera precisa. Uno de los productos que siguió comercializándose de forma rutinaria fue el licor. Las bebidas para departir siguieron consumiéndose, continuando con una costumbre adquirida en siglos anteriores que, al respecto, Patiño ${ }^{33}$ describe como una práctica social a lo largo y ancho del país. Todo ello a pesar de las altas tasas impositivas puestas a la venta de cerveza, que, en 1966, produjo la declaración de José Román Fernández, vicepresidente de las «Cervecerías Barranquilla y Bolívar, Águila S.A.», industria cervecera líder en el país: «La cerveza es un producto de consumo popular y por consiguiente, su precio debe estar de acuerdo con la capacidad de nuestros consumidores.

29 Gaceta del Departamento del Atlántico, Barranquilla, 20 de junio de 1947, 11

30 Ibidem, 138.

31 Ibidem, 139.

32 Ibidem, 143-144.

33 Patiño, 1990, 4. 
En consecuencia, la supervivencia y el desarrollo de la industria cervecera depende en buena parte de que el hábito de su consumo se mantenga no solo a base de calidad — que en Colombia ha sido lograda en alto grado — sino también, de precios competitivos». ${ }^{34}$

De esta manera, la cerveza siguió siendo uno de los productos de mayor venta en las tiendas de barrio, convirtiéndose en un efectivo imán para disipar las penas vividas por los habitantes de las zonas populares de la ciudad. El consumo de licor se incrementaba en épocas decembrinas, de pascua, vacacionales de mediados de año, deportivas y de eventos masivos y populares (Carnavales, Día del amor y la amistad, etc.). ${ }^{35}$ Otra decisión estatal que afectó el consumo en las tiendas de barrio en Barranquilla fue la expedición, en 1972, de la Resolución 198, firmada por el alcalde de la época Eduardo Osío Carbonel y su secretario de gobierno Elías Moisés, en la que se determinaron multas y sanciones a través de la Prefectura de Precios, Pesas y Medidas, causadas por especulación de precios a los consumidores. Ya los consumidores no adquirían los productos en función de lo que necesitaban, sino que todo se desarrollaba de acuerdo con los parámetros fijados en la norma establecida, cometiéndose atropellos y acciones de mala fe por parte de los inspectores de vigilancia: «Los de Precios, Pesos y Medidas, para poder corretear a los tenderos llegaban a la tienda y cargaban unas pesas fallas que les faltaba, cuando eso el peso era de 470 gramos la libra y ellos la cargaban de 420, y entonces llegaban y ponían el peso y eran 420, enseguida hacían la boleta o tocaba ir a la Prefectura, el que no se dejaba extorsionar de ellos, ir a la Prefectura, de todas maneras, allá les tocaba pagar». ${ }^{36}$

34 Diario del Caribe, Barranquilla, 6 de junio de 1966, 1-2.

35 A finales del siglo XX, en una huelga de la Cervecería Águila en Barranquilla, expresaba Mc'Causland, comentarista económico, que los tenderos estaban en crisis en plena pascua por la ausencia de cervezas en las tiendas, describiendo hechos sucedidos como: «Quien llora, dice Aquiles Miranda Márquez, el dueño de la popular tienda Doña Juana, ubicada en el Barrio Abajo y donde en un fin de semana normal se venden veinte cajas de cerveza. Pero este no es un fin de semana normal. La huelga cervecera ha dejado a la ciudad prácticamente seca. La existencia, guardada sigilosamente en las bodegas de los acaparadores, se está acabando. Sentado en la puerta de su tienda, con las mesas guardadas y las fichas de dominó empacadas. Aquiles Miranda está perdiendo unos sesenta mil pesos semanales». Mc'Causland, 1993, 4.

36 Líderes gremiales de la época que expresan sus vivencias y que décadas después recuerdan con claridad, describen las escenas llenas de angustia, confusión y una valentía que no dejó a un lado el fortalecimiento de relaciones de miles de tenderos que ya estaban posicionados en Barranquilla, procuraban defender a coterráneos y a comerciantes así no fuesen oriundos de sus poblaciones, logrando llegar a acuerdos con los entes regulatorios y saliendo ilesos para mantener las puertas abiertas al servicio del barrio. Entrevista a Juan Duarte realizada en Barranquilla el 15 de diciembre de 2013. 
Pese a los esfuerzos colectivos desplegados por parte de la sociedad para acabar con las acciones y la potestad de la Prefectura de Precios, Pesos y Medidas, en 1991 se creó, mediante el Acuerdo 039 del 12 de septiembre, la Inspección de Precios, Pesas y Medidas. Con su creación, como una Inspección de Policía Especial «adscrita al Despacho del alcalde de Barranquilla», se precisaban sus funciones de dirigir, controlar y vigilar el ejercicio del expendio de bienes y servicios, y el uso de pesos e instrumentos para pesar, con el fin de evitar la práctica de «medir incompletos o disminuidos o que en alguna forma tiendan a engañar al público de conformidad con la ley». ${ }^{37}$ Además, al considerar importante cómo el precio, empaques y publicidad de productos y servicios —individual o conjuntamente - afectan la creencia del consumidor de que los beneficios del consumo son la razón de ser en la vida, trabajo y familia. ${ }^{38}$ Su expansión y masificación contribuyó a que estas se fueran quedando sin un control oficial una a una, ${ }^{39}$ viéndose sometidas a variables de otra índole, tales como la capacidad de compra de sus consumidores y las condiciones del entorno socioeconómico donde se localizaban. Factores como los aspectos «climatéricos y culturales» empezaron a ser determinantes en términos de preferencias y prioridades de consumo, tal y como lo expresó Currie: «La pobreza aparente en Barranquilla puede ser en parte el resultado de preferencias en el consumo. Por ejemplo, en un determinado medio climatérico y cultural, el vestuario, la vivienda y los muebles para la casa pueden parecer menos importantes que la cerveza, las gaseosas y el tabaco». ${ }^{40}$ Es claro que el consumo en las tiendas de barrio en Barranquilla ha estado influenciado por aspectos no solo relacionados con los cambios en el modelo de desarrollo económico — por ejemplo, la apertura económica de 1990_, sino por aspectos asociados a las regulaciones y acciones del Estado sobre la consumición o el gasto.

37 Archivo del Concejo Municipal de Barranquilla, Barranquilla, Libro de Acuerdos del Concejo, Acuerdo 039, 12 de septiembre de 1991, 1-7.

38 Belk, 1985, 275.

39 De acuerdo con Altamar, los tenderos han defendido su participación frente a las regulaciones y señalamientos tributarios. En el año 2000, sobre este asunto, señala que el presidente de la Confederación Nacional de Tenderos y Comerciantes (Conaltec), Alejandro Duarte Rueda, pidió, a su turno, la cabeza del director regional de la DIAN, Roque Yidi, porque las resoluciones entregadas a los tenderos eran absurdas, y su sola presentación constituía un atropello contra ese sector que, entre otras cosas, cumplía una importante labor social frente al consumidor final. Altamar, Javier Franco, «Tenderos, no a las Facturas», El Tiempo Digital, Bogotá, 17 de febrero del 2000. Disponible en: http://www. eltiempo.com/archivo/documento/MAM-1267813 [Consultado: 10/11/2019].

40 Currie, 1965, 46. 


\section{Inmigrantes y tradiciones comerciales en la tienda de barrio}

En el manejo de las tiendas de barrio en Barranquilla, se destacan tanto los inmigrantes extranjeros como los comerciantes provenientes de diversos departamentos del interior de Colombia, quienes junto a sus familias estructuraron redes de relaciones socioeconómicas. ${ }^{41}$ La colonia extranjera de mayor impacto en el desarrollo de la tienda de barrio de la ciudad a lo largo del siglo XX fue la conformada por los chinos, quienes, a través de los restaurantes y tiendas de provisión, de manera inicial, servían a inmigrantes chinos, supliendo sus necesidades y gustos. ${ }^{42}$ Los chinos fueron reconocidos en el sector de los pequeños negocios a partir de la consolidación de sus lazos familiares y de la integración de sólidas redes sociales sobre la base de múltiples transacciones de distribución. ${ }^{43}$ Para la década de 1940, los chinos tenían diferentes locales comerciales, bien surtidos de mercancías y con una buena exhibición de los productos expendidos. ${ }^{44}$

Además, los chinos utilizaban estrategias de mercadeo que cautivaron a los consumidores, entre ellas la promoción popular llamada «la ñapa», que describe Dagis Galvís en su historia del barrio de Rebolo:

Los chinos eran muy pacientes para despachar, pero los Revoleros le «mamaban mucho gallo» hablándole a los chinos, cambiándole la $\mathrm{r}$ por 1 , de la siguiente manera: «chino tu comel mucho alo, chino malica». Pero los chinos no «paraban bolas» y seguían atendiendo a sus clientes. Lo que nadie ha podido explicar con claridad es ¿por qué los chinos dejaron las tiendas en Rebolo y se fueron a sembrar hortalizas? Los chinos tenían una libreta a la cual la llamaban «ñapa» y a los buenos clientes que varias veces aparecían apuntados, les regalaban un «guineo» maduro; de ahí la costumbre barranquillera de pedir la «ñapa». Pero dice el «viejo bigote»: eche, los $\operatorname{cachacos}^{45}$ no regalan ni ñapa ni un carajo; son tronco de «duros» (tacaños). ${ }^{46}$

41 En las matrículas mercantiles de la década de los años 70 se detectaron evidencias de tiendas de barrio propiedad de tenderos chinos, como Yin Kou Huie de, Tang Ching Hing Pon, Tang Polo José Alfredo, Chin Robles Tomas Vicente. Sin duda, el dinamismo de esta colonia en el comercio de la época es un innegable aporte al desarrollo del canal tradicional en Barranquilla. Véase en Boletín de la Cámara de Comercio de Barranquilla, Barranquilla, 30 de noviembre de 1973, 1-22.

42 Fleischer, 2012, 75.

43 Siu, 2004, 79.

44 «Por motivo de salud véndese tienda bien surtida y acreditada, en Avenida Boyacá, carrera Vesubio. Yi Seng. Entenderse allí mismo». La Prensa, Barranquilla, 30 de mayo de 1940, 2.

45 En la costa caribe colombiana, se designa con esta expresión al inmigrante procedente del interior del país, quien llega en busca de nuevas oportunidades y de cambios en su estilo de vida. En el interior del país, solo se utiliza distinguir a las personas nacidas en Bogotá, la capital de Colombia. Véase, Páramo, Contreras y Arenas, 2010, 23.

46 Dagis, 1996, 77. 
Después de comprender la importancia de la logística en la entrega de productos, los chinos reorientaron su actividad y se dedicaron a comercializar hortalizas y huevos en la ciudad. Productos que, al ser vendidos de manera masiva en las tiendas de barrio, fueron consolidando las actividades comerciales de alrededor de quince familias de chinos, ubicándose, a partir de 1957, en el km. 12 Vía Puerto Colombia. Estas granjas producían huevos que eran repartidos en sus modernas camionetas. Otras familias se concentraron en el cultivo de hortalizas y se ubicaron en diferentes barrios de la ciudad como: Las Delicias, San Francisco y en amplios sectores de la Vía 40 y La Chinita. Comercializaron verduras variadas, en especial el cebollín, el cilantro y el ají, que fueron las más producidas e igualmente abastecidas en las tiendas de barrio y las plazas del mercado público. ${ }^{47}$

A mediados del siglo XX, a pesar de la pérdida del liderazgo portuario de Barranquilla como resultado de la competencia de Buenaventura, ${ }^{48}$ el comercio en la tienda de barrio seguía en expansión a cargo de los pobladores provenientes del interior del país. Estos fueron desplazando a los chinos en su incesante búsqueda de un mejor porvenir. En su mayoría huían de la inseguridad producida en el centro del país como consecuencia de los angustiosos años de la violencia partidista vivida entre 1948 y $1953 .{ }^{49}$ Los cachacos se ubicaron en las tiendas ${ }^{50}$ de barrio junto con familiares y paisanos, dando rienda suelta a sus anhelos de superación y la construcción de entornos más tranquilos. ${ }^{51} \mathrm{Y}$ la ciudad recibe a quienes querían desarrollarse en ella y salir de las problemáticas internas del país. Así lo manifiesta la revista Barranquilla Gráfica: «Los graves problemas que afrontaron en parte no fueron fracasos exclusivamente barranquilleros. Fueron obra de gratuitos empeños, de insulsos centralismos, manifiestamente alérgicos a la transformación y desarrollo de una ciudad como Barranquilla que no le daba al país otra cosa más que satisfacciones». ${ }^{52}$

47 Los chinos aprovecharon tanto las extensas zonas de tierras planas de los alrededores de Barranquilla, como la cercanía de la ciudad para cultivar productos típicos de los países de Asia Occidental. Entrevista a William Ching realizada en Barranquilla el 5 de mayo de 2014.

48 Meisel, 1987, 65.

49 Kalmanovitz y López, 2007, 22.

50 De acuerdo con lo dicho sobre el ambiente social de Barranquilla, la masiva aparición del cachaco en la costa fue producto de la violencia del pasado y del presente. Buscando la posesión de un terreno donde asentarse, el inmigrante del centro del país se ubicó en las serranías del Perijá y San Lucas y en la Sierra Nevada de Santa Marta. Provenía de los Santanderes, Boyacá, Tolima y Antioquia, y ha sido portador de una mentalidad que valora grandemente la propiedad de la tierra, la organización doméstica de la producción y el progreso. Colombia, país de regiones, 1998.

51 Páramo, 2009, 35.

52 Barranquilla Grafica, Barranquilla, 7 de abril de 1967, 42. 
Después, a partir de 1957, y como consecuencia de la nueva oleada de invasiones de extensos terrenos, privados y públicos — dado el gran déficit de viviendas y el caos producido por las grandes capas de población marginada en busca de adquirir su propia vivienda-, se crearon barrios como El Carrizal (1957), El Bosque (1958), Villate (1960), Las Américas (1962) y La Manga (1963), ${ }^{53}$ que demandaban cada día más el establecimiento de tiendas de barrio ${ }^{54}$ que suplieran sus necesidades básicas. Así, la tienda de barrio fue adquiriendo la connotación de institución social, puesto que los recién creados barrios no disponían de zonas verdes, parques, teatros, cines, ni centros de recreación; algunos poseían canchas de fútbol y en la mayoría de ellos se decía que existían tiendas y tienda-cantinas a las que llegaban los clientes a divertirse sobre todo durante los días festivos y los fines de semana. ${ }^{55}$ Todos los hechos relatados concuerdan con la proposición de Russell W. Belk, Güliz Ger y Soren Askegaard, en un escenario propiciado desde la interacción social al consumo local, así: «Las motivaciones y los esquemas de acción son siempre sociales, es decir, están conformados y expresados en un determinado contexto social, para el caso, en las sociedades modernas, este brote del deseo a menudo toma la forma de consumo; de ahí, la noción de las sociedades de consumo y el deseo del consumidor». ${ }^{56}$

La tienda de barrio fue reafirmando su carácter multipropósito en la que se expendía todo tipo de productos de consumo al por menor. Podían adquirirse también productos artesanales, de consumo masivo e industriales, surtidos por los mayoristas abarroteros - también cachacos-, quienes se situaron en el centro de la ciudad como punto estratégico para ejercer su actividad, a pesar de la negativa de las autoridades barranquilleras respecto a la forma y la logística de distribución de este tipo de productos. ${ }^{57}$ Según Roberto Mc'Causland, líderes políticos de la época como Andrés Gómez Támara, David Castro Seniors, Alberto Pumarejo, Julio Gerlein Comelín, Dario Álvarez Londoño, Alfredo Dávila y Miguel Borrero realizaron gestiones en 1963 para mejoras en la población barranquillera y, entre ellas, develaron que el centro de la ciudad se convirtió en una problemática de

53 Mendoza, 1997, 120.

54 Esta es una de las conclusiones obtenidas de la investigación hecha en 1966 sobre los barrios de invasión El Bosque, Santo Domingo y Carrizal. Se afirma: «Es muy común en los barrios la existencia de pequeñas tiendas de comestibles — puede haber hasta seis en una cuadra—, fenómeno que es bastante corriente en otras ciudades del país». Havens y Usandizaga, 1966, 59.

55 Delfín y Meza, 1978, 6.

56 Belk, Ger y Askegaard, 1975, 329.

57 Contreras y Arenas, 2009, 15. 
grandes proporciones debido a la invasión de muchos negociantes populares y se acusaba a quienes conquistaban con sus prácticas comerciales el consumo masivo y popular, «por ser un mal que ha echado raíces en nuestro medio y se ha grabado en los últimos años por inmigración de gentes, muchas de las cuales encuentran en este absurdo comercio una fácil manera de ganar el diario sustento». ${ }^{58}$

A comienzos de 1980, el número de tiendas de barrio fue creciendo. Según la Zonificación Operativa del Área Urbana de Barranquilla, existían 811 tiendas tradicionales y 632 ventorrillos en los que podría adquirirse en mayor proporción rancho, licores y bizcochería. ${ }^{59}$ Los ventorrillos eran lugares menos estructurados que las tiendas de barrio; se ubicaban en barrios de estrato 1 (bajo-bajo) y estrato 2 (bajo), donde residen contribuyentes subsidiables por el estado. Adecuados a su entorno, en su mayoría eran construidos en madera, con ventanas amplias y un pequeño mostrador debajo de un techo extendido que servía de sombra y donde departían los consumidores, y se acercaban los niños a consumir bolas de dulces artesanales.

A finales del siglo XX, las condiciones urbanísticas fortalecieron mucho los ventorrillos y contribuyeron a legalizar la integración comercial de los cachacos a través de la Colonia Santandereana ${ }^{60}$ y la Antioqueña, identificadas cada una de ellas como Movimientos Cívicos Santandereanos y Movimiento Cívico Paisa. ${ }^{61}$ Hecho que fue socializado en los diarios locales, resaltando su decisión de permanecer en la ciudad. Ya organizados, los cachacos promovieron, desde sus respectivas instituciones sociales, un consumo más responsable y tomaron parte activa en el estímulo al servicio social comunitario, desarrollando también actividades deportivas como mecanismo de integración con sus clientes y de estos con sus propios familiares. ${ }^{62}$

58 Barranquilla Grafica, Barranquilla, 30 de agosto de 1963, 12-14.

59 Zonificación Operativa del Área Urbana de Barranquilla, 1980, II:7-33.

60 El Heraldo, Barranquilla, 30 de abril de 1992, 4.

61 Viloria et al., 1995, 223.

62 De acuerdo con Altamar, justamente Conaltec reúne 17 agremiaciones de origen santandereano como Undeco (Unión de Comerciantes), que agrupa a unos 4.500 tenderos y pequeños comerciantes de Barranquilla; Asaba (que reúne a los abarroteros), Asocentro (a los comerciantes del Centro), Asoparte (distribuidores de repuestos para autos), Asocompaz (comerciantes de la carrera La Paz en el Centro de Barranquilla) y Asocombol (comerciantes del Paseo Bolívar). Altamar, Javier Franco «Se quedaron con las tiendas», El Tiempo Digital, Bogotá, 7 de febrero de 2000. Disponible en: https:// www.eltiempo.com/archivo/documento/MAM-1254787 [Consultado: 10/11/2019]. 


\section{La resistencia de la tienda de barrio frente a los grandes formatos de distribución comercial y a la acción del Estado colombiano}

La función comercial y social de las tiendas de barrio se ha visto amenazada por distintas fuerzas y circunstancias dirigidas a desplazarlas del flujo de productos de consumo masivo, e incluso a hacerlas desaparecer. Es así como, desde mediados del siglo XX, se han venido instalando en Barranquilla múltiples formatos modernos de distribución comercial, como LEY, TIA, SEARS, OLÍMPICA, VIVERO y Cajas de Compensación como COMFAMILIAR. A pesar de que varios de ellos ya no existen porque fueron vendidos o fusionados con otros, desde sus inicios han pretendido desplazar a las tiendas de barrio, brindándole a sus potenciales consumidores comodidad, agradables condiciones climáticas, crédito y mecanismos ágiles y diversos de pago. En el mismo sentido, los pequeños comerciantes vieron la necesidad de agremiarse y fortalecer este segmento de mercado. Así nace «Undeco» (Unión Nacional de Comerciantes) en 1972. Este nuevo órgano gremial, entidad sin ánimo de lucro, representa al sector de pequeños comerciantes ante los estamentos públicos y privados del orden nacional, regional y local. ${ }^{63}$

Por su parte, el gobierno nacional también ha establecido políticas públicas con propósitos similares, aunque con argumentos distintos. A fin de custodiar el consumo de la gran variedad de productos agropecuarios demandados en el país que, por ser de primera necesidad, no deberían ser monopolizados, se crea, a mediados del siglo XX, el «Instituto Nacional de Abastecimiento» (INA), ${ }^{64}$ llamado también «Corporación de Defensa de Productos Agrícolas». Mediante la Ley 5. ${ }^{\mathrm{a}}$, se quiso combatir la carestía de alimentos y la especulación. Esta entidad autónoma de servicio público organizó un formato comercial de consumo masivo - tipo autoservicio-, en el cual, a través de contratar personas para impulsar el consumo libre, pretendía darles seguridad a los consumidores al adquirir los productos de su preferencia.

Para hacer frente a la problemática de consumo local en Barranqui1la, el INA se transformó en una verdadera estrategia de distribución de productos de consumo masivo y popular. El INA importaba de Venezuela productos como trigo, aceites comestibles, azúcar, harina de trigo y sémolas, amparado por el Decreto 1816, con el que se producía la exención de

63 Sanclemente Téllez, 2014, 12.

64 Mendoza, 1999, 142. 
derechos de aduana y de giros con determinadas cantidades de tonelaje. ${ }^{65}$ Por ese entonces, también se promovió un consumo de conveniencia estimulado por el gobierno, entregando subsidios a muchas de las familias que se consideraban necesitadas. Se impulsó también una política de definición de precios que mejoraran los que existían en las tiendas de barrio y en los mercados públicos, y se implementaron servicios a domicilio en los barrios de la ciudad: «su carácter principal lo constituye la ayuda económica que otorga, con la finalidad de cubrir las necesidades que causan los hijos [...] En sentido regional, el subsidio persigue, como objeto básico, la defensa integral de la familia, robusteciendo su importancia en el conglomerado social». ${ }^{66}$

Los productos consumidos por los pobladores en Barranquilla a través del INA, tanto en sus bodegas de expendio oficial como en vehículos ambulantes, fueron: aceite para cocinar, aceite de coco neutro, areparina, arroz, arveja, azúcar sulfitada, avena Quaker, café Almendra, café Universal, café San José, Deli-Arequipe, caldo Maggy y Knorr, Chocavena, chocolate Corona, crema de leche, frijol cabeza negra, frijol algarrobo, harina de avena Quaker, jabón Único, jabón Ideal Azul, jabón Rico Azul y Especial, jugos de frutas de 6 onzas, leche Pelargón, Lactógeno, Nestógeno y Dryco, leche Nido, leche condensada, maíz amarillo y blanco duro y calentano, milo, maicena, Marzol harina de maíz, Nescafé, Nutricia, panela, papa, pastas alimenticias, sal refinada, sopas Maggi y sopas Mondi. ${ }^{67}$

Después del INA, el gobierno recurrió a otras formas de competir con los mercados tradicionales y con las tiendas de barrio a través del IDEMA (Instituto de Mercadeo Agropecuario), de las cajas de compensación familiar, de diversas cooperativas, de algunos fondos de empleados, de los mercados móviles, y de las entidades con sentido social y por tanto protegidas por el Estado. ${ }^{68}$ El gobierno, no contento con la promoción de estos mecanismos de competencia contra los canales tradicionales de distribución, anunció a nivel nacional mediante el ministro de Agricultura, Germán Bula Hoyos, en 1978, su apoyo a los supermercados, precisando: «la necesidad de impulsar las cadenas de mercadeo para sustituir el sistema tradicional de las tiendas de cada cuadra, que encarecen en más de un treinta por ciento

65 Cámara de comercio de Barranquilla, Barranquilla, 7 de octubre de 1957, 1.

66 Diario del Caribe, Barranquilla, 13 de mayo de 1966, 2.

67 Diario del Caribe, Barranquilla, 27 de mayo de 1966, 3.

68 Lanzetta, 1988, 81. 
el precio original de los productos». ${ }^{69}$ Por las mismas acciones estatales, compañías como Sears, desde 1967, disponían de una institucionalizada estrategia de mercadeo a fin de captar el consumo tradicional conocida como «Súper Rayo». ${ }^{70}$ Con ella, los consumidores podían adquirir todo lo que se vendía en las tiendas de barrio y las plazas de mercado, pero con la comodidad de contar con un espacio placentero en el cual, además de adquirir esos productos, recibían bolsas y les ofrecían un formato de pago en cajas no congestionadas. Esto contribuyó a ahondar las diferencias sociales, puesto que fueron creándose compradores que preferían alternativas clasistas de gustos más armoniosos y cuidadosos.

Estrategias de mercadeo similares proliferaron en las grandes cadenas. En 1973, el LEY, el primer almacén de autoservicio de Colombia, fundado en Barranquilla en 1922, focalizaba su publicidad en el cliente, emplazándolo a contrastar precios respecto a otros establecimientos, diciéndoles: «Siempre espera algo de ti: sé amable con un cliente, si es igual en el LEY cuesta menos», fomentando un sentido de economía y servicio que tal vez no estaba tan sistematizado en la tienda de barrio. Para 1980, las Supertiendas Olímpica (SAO), fundadas en 1954 en Barranquilla como farmacias, hacían alarde de las variadas oportunidades que tenían los consumidores de obtener obsequios tan solo por adquirir las marcas que se expendían en sus establecimientos. Esta estrategia se sintetizaba en frases de gran impacto publicitario como la que promovieron en agosto de 1980: $:^{71}$ «todos los días estamos de aniversario, su compra puede salirle gratis, miles... miles de canasta Olímpica [...] obsequios y regalos durante su compra, esté atenta al timbrazo de la suerte; y como lema afirmaban: "en definitiva no hay como súper tiendas olímpica"». Entre los productos estimulados por Supertiendas Olímpica estaban: víveres, arroces, limpieza, verduras, salsamentaría, entre otros. Impulsaban también de forma decidida la marca propia de Olímpica.

En contraste, a finales de la década de los 80 , varias instituciones sociales decidieron apoyar la labor desarrollada por los tenderos de barrio. La Fundación Mario Santo Domingo agrupó a un número considerable de tenderos en 1987 y creó la Proveeduría de Tenderos, cuyos aliados estratégicos fueron varias empresas: Industrias Pimpollo del Caribe Ltda., Carnes Senén Moreno, Verduras Blas Villalba, Condimentos Cacique Ltda, Cesar Hernández y Cía. Ltda, J.J. Restrepo y Cía. Ltda, Pastas Universal y Cía.

69 El Tiempo, Bogotá, 3 de noviembre de 1978, 2.

70 Barranquilla Gráfica, Barranquilla, 13 de septiembre de 1964, 14.

71 Diario del Caribe, Barranquilla, 1 de agosto de 1980, 4. 
Ltda, Café Universal S.A., Coltabaco S.A., Páez y Cía. Ltda, Distribuidora Tropicosta Ltda, Ingenio Risaralda S.A., Agropecuaria Camagüey Ltda, Rubén Roncallo Distribuciones, IDEMA, Cervecería Águila S.A., Industrias Sansón Ltda y Fábrica Nacional de Vinagres Ltda. ${ }^{72}$

Esta Proveeduría de Tenderos fue la que promovió entre los tenderos de barrio variados consumos financieros ligados al crédito microempresarial que fortalecía la estructura física y comercial de sus tiendas, para resguardarse de los ataques provenientes de las grandes superficies y de los cambios promovidos desde las altas esferas gubernamentales. ${ }^{73}$ La tienda de barrio enfatizó el «fiao» entre algunos de sus clientes más cercanos, como una práctica comercial de gran impacto entre la población de menores recursos.

\section{Empresas y marcas en las tiendas de barrio}

En Barranquilla, por ser una ciudad de notable tradición industrial y comercial, las empresas productoras y distribuidoras han establecido lazos permanentes con las tiendas de barrio, haciendo alianzas a partir de la proximidad comercial existente entre las que comparten intereses económicos y sociales. En sus inicios, eran pocos los medios impresos de comunicación masiva existentes en la ciudad, siendo una forma ágil de transmitir estos mensajes una publicación que circulaba a través de las tiendas de barrio: «El Promotor». Este periódico no se voceaba ni se vendía por las calles. Solamente se podía adquirir en la tienda del señor Rafael de la Espriella, junto al mercado público, y en la Imprenta de los Andes donde era editado. ${ }^{74}$

Posteriormente, a mediados del siglo XX, con la aparición de diferentes diarios, la publicidad fue adquiriendo mayor trascendencia en las comunicaciones empresariales. El contenido de estos mensajes era muy diciente frente al papel jugado por las tiendas de barrio y su rol de canal popular

72 El Tenderito de la Fundación Mario Santo Domingo, Barranquilla, 5 de agosto de 1989, 4.

73 La Fundación Mario Santo Domingo impulsó la creación de un órgano para desarrollar al tendero de barrio como líder microempresarial en la década de 1990 al 2000. El director de la época, Marciano Puche Uribe, apoyó a los pequeños comerciantes de la ciudad en la generación de estrategias cooperativas, las cuales fueron copia del modelo de la Fundación Carvajal de Cali-Valle del Cauca. Así, se creó la Proveeduría de Tenderos en Barranquilla, en el barrio la Ciudadela, para después trasladarse a la Gran Central de Abastos «GRANABASTOS en Soledad, Atlántico». Funda Noticias de la Fundación Mario Santo Domingo, Barranquilla, 5 de diciembre de 1988, 6-7.

74 El Promotor, Barranquilla, 11 de noviembre de 1905, 4. 
de distribución. En los avisos publicitarios pagados por el distribuidor del «Jabón de Oro Súper» en los departamentos de Atlántico, Bolívar y Magdalena, se resaltaba la frase: «pídalo en tiendas y expendios». Los útiles escolares, además de ser vendidos en las papelerías, en 1960, también eran mercadeados en tiendas de barrio. Se decía, incluso, que eran cuadernos de mejor calidad en cuanto a la presentación — de cuarenta hojas—, con cartulina fina y resistente, papel de calidad y marginados; la marca más conocida era «Titán». ${ }^{75}$

Para los años 1977 y 1978, en Barranquilla, la empresa Café Universal publicitaba la alianza que sostenía con diferentes tiendas y sus propietarios: Heberto Camelo de la tienda «Los Suspiros» (calle 68, n. $\left.{ }^{\circ} 29-04\right)^{76}$ y Estela Guarín de la tienda «La Linda» (Kra 44, n. ${ }^{\circ}$ 65-64). ${ }^{77}$ Esta empresa, fundada en Barranquilla en 1939, anunciaba en el Diario del Caribe el lema de su campaña: «Su sabor no lo cambio por nada». Algunos de los productos de notorio consumo popular y asociados con sus respectivos eslóganes publicitarios, que fueron distribuidos en las tiendas de barrio a lo largo del siglo XX, fueron: - Band-Ita: «Evite una infección. ¡Protéjase!, cubra la rozadura con Band-Ita Johnson \& Johnson». ${ }^{78}$-Palmolive: «Para bien de su belleza Palmolivese de pies a cabeza [...] Plan Palmolive 14 días. Compre hoy mismo jabón embellecedor Palmolive». ${ }^{79}$ —Crema Dental Pepsodent: «La del preludio de un romance, la sonrisa Pepsodent, más de un hombre ha perdido la cabeza por la hechicera sonrisa Pepsodent. Pepsodent con Irium hace lucir los dientes más brillantes porque Pepsodent deja los dientes más limpios que cualquier otro dentífrico $[\ldots] \gg .^{80}$ —Jabón LUX: «[... es el jabón de belleza preferido por 9 de cada 10 estrellas de Hollywood [...] LUX es intensamente perfumado». ${ }^{81}$ - Colgate Fluoride: «[...] única en Colombia con fluoruro estanoso, el ingrediente más efectivo para evitar la caries dental [...]». ${ }^{82}$ - Aceite $\mathrm{Z}$ : «El detalle del buen gusto. Aceite fino para la mesa. Producto Fagrave». ${ }^{83}$ — La Insuperable: «Harina de trigo, de Barranquilla, Colombia, Sur América». ${ }^{84}$-Pielroja: «Fumemos Piel-

\footnotetext{
75 Diario la Prensa, Barranquilla, 23 de junio de 1960, 5.

76 Diario del Caribe, Barranquilla, 11 de noviembre de 1977, 7.

77 Diario del Caribe, Barranquilla, 3 de enero de 1978, 2.

78 Diario La Prensa, Barranquilla, 31 de octubre de 1950, 5.

79 Diario La Prensa, Barranquilla, 11 de octubre de 1950, 3.

80 Diario La Prensa, Barranquilla, 20 de octubre de 1955, 7.

81 Diario La Prensa, Barranquilla, 30 de octubre de 1955, 9.

82 Diario del Caribe, Barranquilla, 8 de mayo de 1965, 7.

83 Boletín de la Cámara de Comercio de Barranquilla, 22 de marzo de 1960, 9.

84 Boletín de la Cámara de Comercio de Barranquilla, 27 de agosto de 1966, 7.
} 
roja. Vivamos agradablemente». ${ }^{85}$ —Salsa de tomate California: «[...] don Tomate California, que sí sabe, aconseja: con salsa de tomate California (cátsup) da usted un exquisito sabor a sus comidas, porque la salsa de tomate California ... es auténtica salsa de tomate de la mejor selección [...]». ${ }^{86}$ —Leche: «La leche es vida es energía. Es el alimento completo. Comité Regional de Procesadores y productores de Leche de la Costa Atlántica. Apartado aéreo 5335. Teléfono 29962. Barranquilla». ${ }^{87}$-Cerveza Águila: «Al que tiene tienda... ¡Que lo atiendan! [...] A su salud tendero!». ${ }^{88}$ —Postobon: «Se vincula al día nacional del tendero». ${ }^{89}$ —Nestlé: «Hoy es un gran día para Nestlé. En todo el país. Hoy día del tendero [...] Hoy queremos agradecer la dedicación, el servicio y ese gran espíritu humano de los miles de hombres y mujeres quienes día a día, tras un mostrador, construyen la historia de los barrios, la historia de Nestlé». ${ }^{90}$

Estos contenidos publicitarios, que develan el consumo simbólico de la época, fueron productos elaborados, en su mayoría, por empresas multinacionales y otras nacientes compañías barranquilleras, las cuales marcaron sin lugar a duda la preferencia de consumo durante el siglo XX. Pero los tenderos no quedaron atrás en el mercado tradicional y aumentaron la variedad de productos a ofrecer. Uno de los casos de éxito de tenderos líderes en la industria de consumo masivo fue don Juan Sanabria, tendero que inició su negocio en el barrio Rebolo, poniendo en medio de su tienda un molino de moler maíz que en su proceso migratorio se trajo de Santander. Con el maíz tostado comenzó a preparar una especie de condimento, el cual empezó a vender en su tienda en pequeñas bolsas donde ofrecía pimienta y comino. Sin un nombre que identificara el producto, la gente comenzó a decirle: «véndame esa vaina que tu vendes para sazonar»; así nació la palabra Sasoned. El condimento Sasoned logró un reconocimiento a nivel nacional como producto y llegó a manos de empresas multinacionales. El producto que nació en una calle de Barranquilla, fabricado de manera artesanal por campesinos tenderos, logró rápidamente una proyección internacional. Las expectativas del negocio crecieron, y el sazonador pronto se vendió en

85 Boletín de la Cámara de Comercio de Barranquilla, 9 de febrero de 1960, 22.

86 Diario del Caribe, Barranquilla, 14 de junio de 1965, 9.

87 Publicidad del comité regional de procesadores y productores de leche de la costa atlántica, Revista Quillan, Barranquilla, 30 de octubre de 1975, 12.

88 El Heraldo, Barranquilla, 30 de abril de 1993, 10.

89 El Heraldo, Barranquilla, 30 de abril de 1994, 7.

90 El Heraldo, Barranquilla, 30 de abril de 1993, 10. 
mercados de países como Bolivia, Ecuador y Perú. ${ }^{11}$ Juan Sanabria comercializó su condimento en varios países y poblaciones, «pero sin dejar nunca la tienda».

\title{
Las representaciones en el negocio al por menor de la tienda de barrio
}

Al inicio de la década de 1900, las casas comerciales eran las líderes de los anuncios de sus alimentos de consumo masivo en Barranquilla, sobresaliendo la empresa de Pablo E. Vengochea y C. ${ }^{\text {a: }}$

\begin{abstract}
Anuncio. Tiene a la venta a los mejores precios: Cerveza y abridores de latas; encurtidos, alcaparras, cemento romano, cañamón y betún. Vino jerez y Moscatel; Brandy 3 estrellas y harina «San Luis», salchichón de Vieh, alpiste, kerosene, arroz, fósforos, mantequilla, maicena, puntillas, vasos, sardinas, salmón, vino San Julien, canela en polvo, atún, langosta, leche condensada, loza, jabón Americano, ciruelas pasas, Anís del Mono, linternas, garbanzos, galletas de soda, tinteros y emulsión, harina preparada, cigarrillos, café, turrón de Jijona y alicante, chocolate Osgood, aceitunas, jaleas de membrillo, ciruela, albaricoque, dulces en frascos, frutas en su jugo, sardinas, mortadela y jamón del diablo. (Calle del Banco). ${ }^{92}$
\end{abstract}

Para el año 1955, el departamento del Atlántico ocupaba el tercer lugar en ventas per cápita con $\$ 1.120$ sobre la media de Colombia que era de $\$ 702,{ }^{93}$ lo que reflejaba la fortaleza comercial y flujo económico de la ciudad. En esta década, en el año 1952, la comercialización de productos sufrió una carestía, modificándose al alza los precios de los alimentos de acuerdo a la Cámara de Comercio de Barranquilla:

La panela aumentó $\$ 5$, por carga y 5 centavos por unidad; maíz amarillo se registró un aumento de $\$ 2$, por arroba y 10 centavos por la libra; pescado seco aumento $\$ 30$, por el ciento y 30 centavos por unidad; el arroz aumento de $\$ 23$ por quintal y 30 centavos por libra; panela alza de $\$ 30$, por carga y 20 centavos por libra; yuca aumento $\$ 15$ por carga y $\$ 0,20$ la libra; leche aumento de $\$ 0,10$ por litro. ${ }^{94}$

Y como medidas comerciales, la División de Producción Nacional del Ministerio de Fomento advirtió en este mismo período: «la prohibición

91 Boletín de la Cámara de Comercio de Barranquilla, enero-febrero de 1983, 9-11.

92 Rigoletto. Literatura, Comercio y Variedades, Barranquilla, 8 de julio de 1902.

93 Boletín de la Cámara de Comercio de Barranquilla, 8 de noviembre de 1995, 2.

94 Boletín de la Cámara de Comercio de Barranquilla, 15 de julio de 1957, 3. 
de imponer o cobrar gravámenes de cualquier clase o denominación a la producción y tránsito de los artículos de primera necesidad, según Ley 20 de 1946, tales como: papa, arroz, frutas, legumbres, plátanos, lentejas, garbanzos, arvejas, azúcar, panela, leche y sus derivados, frijoles, maíz, pan, pastas alimenticias, etc.». ${ }^{95}$

En la década de los años sesenta era muy común en los barrios la existencia de pequeñas tiendas de comestibles — «puede haber hasta seis en una cuadra»-, fenómeno que era bastante corriente en otras ciudades del país. ${ }^{96}$ Sin duda, este consumo también ha estado influido por la baja capacidad adquisitiva de los núcleos familiares ubicados en su contexto inmediato, donde se encuentra el mayor número de ellas y donde se continúan practicando los hábitos de adquisición asociados al «arte de comprar barato», propios de este segmento poblacional. ${ }^{97}$ En la Zonificación Operativa del Área Urbana de Barranquilla, 1978-198098 se desveló un escenario de liderazgo de la tienda de barrio tradicional frente a otro tipo de negocios reconocidos en el canal de 1972, establecimientos incluidos en el estudio de forma aleatoria por zonas. El $73 \%$ eran tiendas de barrios y ventorrillos y el $27 \%$ representaba el total de almacenes, carnicerías, boticas y droguerías, entre otros de este tipo de negocios y, de acuerdo a las agrupaciones de dígitos comerciales: 6.199 distribuidores de frutas, $90 \%$; 6.152 ranchos, licorerías, etc., $68 \%$; 6.151 almacenes de granos y vegetales, $59 \%$.

En el país existen tiendas de barrio donde es posible comprar al granel productos, como un valor agregado fuertemente poderoso originado en los años setenta y ochenta. ${ }^{99}$ En el año 1982, el estudio de La economía de la tienda de barrio ${ }^{100}$ sobre el comportamiento de su gestión, la mostró como una actividad rentable y masivamente utilizada por los consumidores. Los autores concluyeron que este tipo de negocio tradicional era la conformación de una unidad económica familiar, de ingresos medios y bajos, cumpliendo con un papel importante especialmente en el estrato social más pobre. Durante 1983, los investigadores Álvaro García García y Luis Gabriel Rincón escribieron sobre la tienda de barrio que:

95 Boletín de la Cámara de Comercio de Barranquilla, 29 de julio de 1957, 2.

96 Usudizaga y Havens, 1966, 59.

97 Diario del Caribe, Barranquilla, 1 de junio de 1966, 6.

98 Zonificación Operativa del Área Urbana de Barranquilla, 1980, II:9.

99 Herrera, 2010, 88.

100 La economía de la tienda de barrio. Primer concurso de Investigación comercial, 1982, 57. 
En la ciudad que más del $75 \%$ de las tiendas existentes estaban conformadas por grupos familiares y solo un $24,83 \%$ representaban a no familiares y/o tendero solo con apoyo de independientes, y estos miembros con niveles de alfabetismo superiores al $95 \%$ en estos puntos comerciales, que a pesar de estas condiciones funcionales las rentas promedio mensual según estratos fueron: a) Bajo-bajo: $\$ 191.711$, b) Bajo: \$ 424.658, c) Medio Bajo: \$ 635.483, d) Medio: \$ 833.526, rentabilidades comparadas con el salario mínimo de este mismo año 1983 de valor de $\$ 9.261,{ }^{101}$ consideraba para el tendero una renta significativa entre un $20 \%$ y $90 \%$ a lo que un trabajador dependiente recibía legalmente en la ciudad. ${ }^{102}$

Durante la última década del siglo $\mathrm{XX}$, la presentación de los productos en la tienda de barrio alineó los productos de consumo masivo y populares con otros debidamente sellados y presentados adecuadamente en empaques de manera miniaturizada, según señalan Eduardo Páez Barreto y Patricia Pérez Gracia en el estudio «Acercamiento al Comportamiento al Tendero». Se detallaron los productos y marcas de empresas, escogiéndose los de mayores márgenes de diferencia en costos tienda de barrio versus supermercado:

a) salsa de tomate y mayonesa: en la tienda de barrio eran sobres de 50 gr precio de venta $\$ 500$, y en el supermercado doy pack de $\$ 1.000$ gr a $\$ 7.670$, con un precio de venta mayor de $\$ 347$ por cada 50 gr puesto a la venta en la tienda, b) pastilla de chocolate: en la tienda de barrio una pastilla de 31,25 gr. precio de venta $\$ 250$, y en el supermercado una libra a $\$ 3.290$, con un precio de venta mayor de $\$ 24$ por cada gramo puesto a la venta en la tienda, c) salchicha: en la tienda de barrio botella de aceite de $250 \mathrm{cc}$ precio de venta $\$ 1.300$, y en el supermercado botella de aceite de $1.000 \mathrm{cc}$ precio de venta $\$ 3.850$, con un precio de venta mayor de $\$ 337$ por cada $250 \mathrm{cc}$ puesto a la venta en la tienda, d) café: en la tienda de barrio eran sobres de 1,5 gr precio de venta $\$ 150$, y en el supermercado paquete de 85 gr a $\$ 3.090$, con un precio de venta mayor de $\$ 95$, por cada 1,5 gr puesto a la venta en la tienda, e) Jabón de ropa: en la tienda de barrio bolsa de 125 gr precio de venta $\$ 700$, y en el supermercado bolsa de $3 \mathrm{~kg}$ precio de venta a $\$ 14.000$, con un precio de venta mayor de $\$ 586$ por cada 125 gr vendidos en la tienda. ${ }^{103}$

De acuerdo al impacto en la historia comercial, el papel que servía para empacar una cantidad mínima de harina, azúcar y granos, entre otros, al igual que productos líquidos como el aceite, detergentes, etc., pasaba de ser una tarea del tendero para convertirse en una estrategia de mercado, pues al entregar los productos miniaturizados y empacados correctamente

101 Decreto 3713 de 1982.

102 García y Rincón, 1982, XX.

103 Páez y Páez, 2006, 14-15. 
ganaban mayores rentabilidades para sus empresas, costo que asumían los consumidores, quienes por la cultura de consumo al granel y los costos de vida de la ciudad se veían obligados a realizar compras de tipo racionalizadas a su nivel de ingresos.

\section{Consideraciones finales}

La tienda de barrio durante el siglo XX fue, sin duda, un contexto de comercialización tradicional de uso masivo por todo tipo de estratos en el entorno socio-económico barranquillero. Y aunque su negocio brinde pocos beneficios económicos en términos de utilidades, presta a la familia el servicio de hacerse a los víveres según precios mayoristas y es en busca de este beneficio que, parece, proliferan las tiendas de comestibles. ${ }^{104}$ La necesidad de conocer y contar lo que sucedió en el devenir histórico colombiano ha propiciado los elementos integradores suficientes para dimensionar el pasado del que se proviene, y al que, por más que se quiera, no se puede renunciar: «Los estudios no constituyen muestras aleatorias de posibles situaciones y no siempre reflejan la gama completa de dimensiones situacionales recién delineadas, a pesar del hecho que la mayoría de los hallazgos se han basado en fuentes relacionadas para analizar hechos relacionados, el argumento es sin duda válido sobre cualquier demostración del comportamiento de quienes son parte de los grupos». ${ }^{105}$

Los riesgos que se asumen son altos cuando, parados en la perspectiva de los «vencidos», se terquea en el develamiento del papel de formatos comerciales en los que se reflejan las raíces culturales que tipifican a Colombia y que por lo mismo se niegan a desaparecer de la vida del vecindario, no obstante los ataques que desde diferentes ángulos se les ha hecho a lo largo de su propia dinámica comercial. ${ }^{106} \mathrm{El}$ siglo XX ha sido vital para comprender su estoica resistencia y su obstinada presencia gracias al fenómeno de consumo tejido a su alrededor y a las particulares conexiones establecidas

104 Usudizaga y Havens, 1966, 59.

105 Belk, 2003, 158.

106 En 1992, llegó a Colombia Henry Salen, especialista del comercio mundial, y vaticinó que a comienzos del siglo XXI no existirían las tiendas de barrio ni las centrales de abasto en el país. Casi una década después, Salen regresó a Colombia a explicar cómo negociar con el canal tradicional y tuvo que reconocer que había subestimado el factor cultural cuando predijo el fin de los tenderos. «La tienda no se rinde», Dinero, Colombia, 27 de junio de 2003. Disponible en: http://www.dinero.com/ edicion-impresa/negocios/articulo/la-tienda-rinde/6238 [Consultado: 07/05/2019]. 
entre consumidores y tenderos. La herencia social y cultural contribuyó a darle vida a las tiendas de barrio que, abiertas a todo tipo de público y en cualquier lugar de la ciudad, implementaron múltiples prácticas comerciales como la de prestar un servicio rápido y de corta distancia. Además, los tenderos de barrio lograron comprender lo que los pobladores y consumidores requerían, aprendiendo a verlos como sus vecinos y amigos más que como sus clientes.

Así, fue posible conocer las noticias del día y las características de los artículos más especializados, en combinación con múltiples servicios financieros y de integración social. Se buscaba siempre conectar los sentimientos populares con la memoria y la propia identidad del consumidor. Entonces, el consumo de la tienda de barrio no está relacionado solo con la compra de productos, sino también con la fortaleza de relaciones a través de servicios externos como: a) la miniaturización: que es el ajuste de los productos para lograr satisfacer las necesidades de consumo y la capacidad económica de quienes consumían en ella; b) la financiación: en sentido de un crédito popular denominado «credimarlboro», a registrar los compromisos de deudas de los clientes que formaban parte del negocio; c) la recreación: como punto de tertulias y encuentros de actividades barriales; d) ampliar la distribución y circulación, ubicada en cada esquina de barrios, manteniendo una estrategia de cercanía con los clientes, establecida en lugares equidistantes, de difícil acceso y de baja seguridad. Y servicios internos para quienes la conforman: a) propulsor socio-económico: como negocio familiar los miembros se benefician en la rentabilidad que ella produce, mejorando su estilo de vida; b) desarrollador de habilidades comerciales: como un medio para generar experticia y habilidades en la comercialización de bienes y servicios de consumo masivo; c) referencia del modelo comercial: para que con la permanencia y desarrollo del negocio de la tienda de barrio otros generen la escogencia de ser tenderos y tomar los elementos de éxito de quienes la mantienen.

Finalmente, es evidente la existencia de la tienda de barrio tradicional constituida como una institución social que se auto reproduce. La tienda de barrio no es solo una unidad económica a través de la cual circulan los bienes y servicios que la comunidad demanda, sino que es el resultado de una trama popular sobre la cual se ha estructurado la vida de los habitantes de los barrios, y de quienes de una u otra forma van llegando en busca de su propio bienestar presente y futuro. 


\section{Agradecimientos}

Este artículo se integra en el Proyecto No DI-0018 denominado «Historia Empresarial de Barranquilla y del Caribe Colombiano», como parte del segundo ciclo de una primera publicación (Páramo y Contreras, 2014). Estas investigaciones se han desarrollado con la participación del Grupo de Investigación en Marketing GIM (A1 Colciencias) y miembros de la Escuela de Negocios de la Universidad del Norte. Expresamos nuestra gratitud a los funcionarios del Archivo Histórico del Atlántico, así como a los tenderos comerciantes minoristas de Barranquilla.

Recibido, 24 de julio de 2018 Segunda versión, 22 de mayo de 2019 Aceptado, 17 de julio de 2019

\section{Referencias Bibliográficas}

Barriga, David y Barriga, David Jr., Recuerdos del Barrio Abajo, Barranquilla, Editorial Autores, 2013.

Belk, Russell, «Situational Variables and Consumer Behavior», Journal of Consumer Research, 2:3, Oxford, 1975, 157-164.

Belk, Russell, «Materialism: Trait Aspects of Living in the Material World», Journal of Consumer Research, 12, Oxford, 1985, 265-280.

Belk, Russell; Ger, Güliz y Askegaard, Søren, «The Fire of Desire: A Multisited Inquiry into Consumer Passion», Journal of Consumer Research, 30, Oxford, 2003, 327-350.

Colombia, país de regiones, tomo I, Santa Fe de Bogotá, Centro de Investigaciones y Educación Popular, Colciencias, 1998. Disponible en: http://www. banrepcultural.org/blaavirtual/geografia/region1/cap9b.htm [Consultado: 08/10/2019].

Contreras Cuentas, Margarita María y Arenas Osorio, José Herminzo, «Evolución y Práctica del Negocio de Tiendas y Depósitos en El Departamento del Atlántico», tesis de pregrado dirigida por Dagoberto Páramo Morales, Barranquilla, Universidad del Norte, Escuela de Negocios, 2009.

Currie, Lauchlin, Plan socioeconómico para el Atlántico, Bogotá, Imprenta Nacional, 1965.

Dagis Galvís, Alcides, Historia de mi querido barrio Rebolo, Barranquilla, Archivo Histórico del Atlántico, 1996.

Delfín Mosquera, José y Meza Silva, Luz, «Aspecto legal de la tenencia de tierras en las zonas de invasión en la ciudad de Barranquilla», tesis de pregrado 
dirigida por Gustavo Vergel Cabrales, Barranquilla, Corporación Universitaria de la Costa-CUC, Departamento de Arquitectura, 1978.

Dholakia, N.; Dholakia, R. y Chattopadhyay, «A India's Emerging Retail Systems: Coexistence of Tradition and Modernity», Journal of Macromarketing, 32:3, Kingston, 2012, 252-265.

Dominique, Valentin y Gomez-Corona, Carlos, Methods in Consumer Research, Duxford/Cambridge, Woodhead Publishing, 2018.

Fábregas Molina, Wilber, Historia de mi barrio San Roque, Barranquilla, Archivo Histórico del Atlántico, 1996.

Fleischer, Friederike, «La diáspora china: un acercamiento a la migración china en Colombia», Revista de Estudios Sociales, 42, Bogotá, 2012, 71-79. Disponible en: http://www.redalyc.org/pdf/815/81523235007.pdf [Consultado: 07/05/2019].

García García, Álvaro, «Estudio económico de las tiendas de barrio en la ciudad de Barranquilla», tesis de pregrado dirigida por Luis Gabriel Rincón, Barranqui1la, Corporación de la Costa CUC, Facultad de Economía, 1984.

Gutiérrez Ramos, Jairo, «Tres empresarios coloniales de la Sabana de Bogotá (1538-1790)», en Dávila L. de Guevara, Carlos (comp.), Empresas y empresarios en la historia de Colombia, siglos XIX-XX. Una colección de estudios recientes, tomo I, Bogotá, Universidad de los Andes, 2003, 285-315.

Havens, Eugene y Usandizaga, Elsa, Tres barrios de invasión, estudio de nivel de vida y actitudes en Barranquilla, Bogotá, Ediciones Tercer Mundo, 1966.

Herrera, Camilo, Consumiendo. Introducción al consumo y al consumidor colombiano, Bogotá, Ediciones Alfaomega, 2010.

Hofstede, Geert, «Management Scientists Are Human», Management Science, 40:1, Catonsville, 2008, 4-13.

Kalmanovitz, Salomón y López, Enrique, Aspectos de la agricultura colombiana en el siglo XX, Bogotá, Fondo de Cultura Económica/Banco de la República, 2007.

La economía de la tienda de barrio. Primer concurso de Investigación comercial, Medellín, Fenalco Antioquia, Subdirección de Investigaciones y Planeación, 1982.

Lanzetta, Cristina, «El Comercio Subsidiado», en Lora, E., y Ocampo, J. (eds.), El Sector Comercio en Colombia. Estructura y Comportamiento, Bogotá, Editorial Fenalco-Fedesarrollo, 1988, 80-110.

Meisel, Adolfo, «Por qué se disipó el dinamismo industrial de Barranquilla», Lecturas de Economía, 23, Medellín, 1987, 57-84.

Mendoza Villalobos, Gilberto, Diagnóstico del mercadeo agrícola y agroindustrial en Colombia: Una estrategia para la reactivación de la agricultura, Bogotá, Editorial Fundación Universidad Jorge Tadeo Lozano,1999.

Mendoza, Cesar, «Barranquilla durante el Frente Nacional, 1958-1974», en Zambrano, R. (coord.), Historia general de Barranquilla. Sucesos, Barranquilla, 
Academia de la Historia de Barranquilla/Editorial Mejoras, tomo I, 1997, 119-133.

Navas Ríos, María Eugenia; Londoño Aldana, Emperatriz y Ruiz Navas, Daniel, Canal tradicional de productos de gran consumo, Cartagena de Indias, Editorial Universitaria, 2014.

Páez Barreto, Jorge Eduardo y Pérez Gracia, Patricia, «Acercamiento al comportamiento del tendero», tesis de maestría dirigida por Enrique Luque Carulla, Bogotá, Universidad de los Andes, Facultad de Administración, 2006. Disponible en https://repositorio.uniandes.edu.co/handle/1992/8916 [Consultado: 08/10/2019].

Palacios, Marco y Safford, Frank, Colombia. País fragmentado, sociedad dividida, Bogotá, Norma, 2002.

Páramo Morales, Dagoberto, «Le commerce traditionnel colombien: un espace de renforcement culturel pour le consommateur», tesis doctoral dirigida por Michelle Bergadaà, Genève, HEC Université de Genève, Faculté des Sciences Économiques et Sociales, 2009. Disponible en https://archive-ouverte.unige. ch/unige:10700 [Consultado: 23/11/2018].

Páramo, Dagoberto; Contreras Cuentas, Margarita y Arenas Osorio, José, Canal tradicional en Barranquilla, Origen y Evolución, Barranquilla, Editorial Mejoras, 2010.

Páramo, Dagoberto y Contreras, Margarita, «Las tiendas de barrio en Barraquilla, 1870-1945», en Ferro Bayona, Jesús; Ibarra Consuegra, Octavio y Gómez-Araujo, Eduardo (eds.), Historia Empresarial de Barranquilla (1880-1980). Vol. 1, Barranquilla, Editorial Universidad del Norte, 2014, 103-152.

Patiño, Víctor Manuel, Historia de la cultura material en la América equinoccial, tomo 6, Bogotá, Editorial Instituto Caro y Cuervo, 1990.

Quevedo, Gustavo, El empresariado ante el desarrollo económico de Barranquilla y su incidencia en el factor de cambio, Barranquilla, Centro de Investigaciones, Consultorías y Asesorías (CICADE), 1994.

Ramírez Plazas, Elias, «¿Por qué las tiendas de barrio en Colombia no han fracasado frente a la llegada de las grandes cadenas de supermercados?», Entornos, 21, Colombia, 2008, 37-50.

Reardon, Thomas et al., «The rise of supermarkets in Africa, Asia, and Latin America» American Journal of Agricultural Economics, 85:5, Oxford, 2003, $1140-1146$.

Saini, Gordham K. y Sahay, Arvind, «Comparing retail formats in an emerging market: Influence of credit and low price guarantee on purchase intention», Journal of Indian Business Research, 6:1, India, 2013, 48-69. Disponible en: https://doi.org/10.1108/JIBR-03-2013-0026 [Consultado: 07/05/2019].

Salcedo, Andrés, Barrio Abajo, el barrio de donde somos todos, Barranquilla, Editorial La Iguana Ciega, 2008. 
Sanclemente Téllez, Juan, «Los pequeños distribuidores minoristas y su aporte en la realización de Negocios Inclusivos en Colombia», Revue Interventions économiques / Papers in Political Economy, 50, Quebec, 2014. Disponible en: http://journals.openedition.org/interventionseconomiques/2301 [Consultado: 07/05/2019].

Siu, Lok, «Panamá, El Ferrocarril, la tienda y el barrio», en Morimoto, Amelia, Cuando Oriente llegó a América. Contribuciones de inmigrantes chinos, japoneses y coreanos, Washington D. C., Banco Interamericano de Desarrollo, 2004, 79-98. Disponible en: https://publications.iadb.org/handle/11319/219 [Consultado: 07/05/2019].

Truyol, Tomas, «Comerciantes y casas comerciales relacionados con las actividades financieras en una ciudad caribeña de Colombia durante la segunda mitad del siglo XIX», Anuario de Historia Regional y de las Fronteras, 20:1, Colombia, 2015, 141-160.

Usudizaga, Elsa y Havens, Eugene, Tres barrios de invasión. Estudio a nivel de vida y actitudes en Barranquilla, Bogotá, Ediciones Tercer Mundo/Facultad de Sociología Universidad Nacional, 1966.

Vidal, Antonino y D’Amato, Guissepe, «Comerciantes italianos en Barranquilla, 1905-1919», Caribbean Studies, 42:1, Puerto Rico, 2014, 163-182.

Viloria Terán, Andrés; De la Torre, Zenith y Guardiola Barros, Ricardo, Estudio sociológico y documental para una monografía histórica de la ciudad, Barranquilla, Editorial Efemérides, 1995.

Zambrano, Fabio, «La navegación a vapor por el río Magdalena», Anuario Colombiano de Historia Social y de la Cultura, 9, Barranquilla,1979, 63-75.

Zarante Maldonado, Hilda, «El desarrollo económico y social de Barranquilla 1950-1960», tesis doctoral dirigida por Jairo Parada Corrales, Barranquilla, Universidad del Norte, División de Ciencia de Administración, 2007. Disponible en http://manglar.uninorte.edu.co/handle/10584/165 [Consultado: 08/10/2018].

Zonificación operativa del área urbana de Barranquilla, 1978-1980, Barranquilla, Servicio Nacional de Aprendizaje-SENA, 1980. 